\title{
New sesquiterpenes, JBIR-27 and -28, isolated from a tunicate-derived fungus, Penicillium sp. SS080624SCf1
}

\author{
Keiichiro Motohashi $^{1}$, Junko Hashimoto ${ }^{1}$, Shigeki Inaba ${ }^{2}$, Shams Tabrez Khan ${ }^{1,3}$, Hisayuki Komaki ${ }^{1,3}$, \\ Aya Nagai ${ }^{1}$, Motoki Takagi ${ }^{1}$ and Kazuo Shin-ya ${ }^{4}$
}

In the course of our screening program for novel metabolites from tunicate-derived fungi, novel sesquiterpenoids, named JBIR27 (1) and -28 (2), together with known sporogen-AO1 and phomenone, were isolated from the culture broth of Penicillium sp. SS080624SCf1. The structures of 1 and 2 were determined to be eremophilane analogs on the basis of extensive NMR and MS analyses. Sporogen-AO1, phomenone and 2 showed cytotoxicity against human cervical carcinoma cell line $\mathrm{HeLa}$ at $\mathrm{IC}_{50}$ values of $8.3,19$ and $92 \mu \mathrm{m}$, respectively, whereas 1 was inactive at a concentration of $80 \mu \mathrm{m}$.

The Journal of Antibiotics (2009) 62, 247-250; doi:10.1038/ja.2009.21; published online 13 March 2009

Keywords: cytotoxicity; JBIR-27; JBIR-28; Penicillium sp.; terpenoid; tunicate

\section{INTRODUCTION}

Many bioactive substances have been isolated from marine organisms, such as marine microorganisms, phytoplankton, algae, sponges and tunicates. Moreover, marine microorganisms have been studied as the important resources for new biologically active metabolites. ${ }^{1}$ Especially, marine-derived fungi are emerging as an attractive source for discovering new bioactive compounds. ${ }^{2}$ Indeed, cytotoxic metabolites, such as diketopiperazine alkaloids, ${ }^{3}$ trichodermatides ${ }^{4}$ and carbonarones, ${ }^{5}$ have been isolated from metabolites of marine-derived fungi. Tunicates are a rich source of unique and biologically active metabolites. ${ }^{1}$ However, there have been few reports of compounds isolated from tunicate-derived fungi. ${ }^{6,7}$ Therefore, we attempted to isolate fungi from a tunicate, Didemnum molle, and obtain secondary metabolites from the fungal culture broths.

In the course of chemical screening for novel compounds from the metabolites of tunicate-derived fungi, we isolated two novel sesquiterpenoid compounds, designated as JBIR-27 (1) and -28 (2), from the culture broth of Penicillium sp. SS080624SCf1 (Figure 1). In addition, we also isolated known derivatives, sporogen-AO1 ${ }^{8}$ and phomenone ${ }^{9}$ (Figure 1). This paper describes the fermentation, isolation and brief biological activity of 1,2 , sporogen-AO1 and phomenone, in addition to the taxonomy of the producing microorganism. The structure elucidation of $\mathbf{1}$ and $\mathbf{2}$ is also reported.

\section{RESULTS AND DISCUSSION}

Taxonomy

The sequence analysis of ribosomal DNA and ITS region of the producing fungus showed high sequence similarities with Penicillium sp. strain NRRL 32575 (DQ123664, 99.6\%) and Penicillium roseopurpureum strain NRRL 2064 (AF033415, 98.2\%). Moreover, this strain showed morphological features typical to the genus Penicillium, such as penicillate conidiophore, verticillate phialides and phialides forming basipetal chains of dry conidia. On the basis of the characteristics described above, the strain SS080624SCf1 was identified as a member of the genus Penicillium.

\section{Fermentation}

Penicillium sp. SS080624SCf1 was cultivated in 50-ml test tubes containing $15 \mathrm{ml}$ of the seed medium. The test tubes were shaken on a reciprocal shaker ( 355 r.p.m) at $27^{\circ} \mathrm{C}$ for 3 days. Aliquots $(5 \mathrm{ml})$ of the seed culture were inoculated to 500-ml Erlenmeyer flasks containing the production medium and incubated in static culture at $27^{\circ} \mathrm{C}$ for 14 days.

\section{Isolation}

The culture broth (10 flasks) was extracted with $80 \%$ aqueous $\mathrm{Me}_{2} \mathrm{CO}$. After concentration in vacuo, the aqueous concentrate was extracted with EtOAc. After drying over $\mathrm{Na}_{2} \mathrm{SO}_{4}$, the EtOAc layer was evapo-

\footnotetext{
${ }^{1}$ Biomedicinal Information Research Center (BIRC), Japan Biological Informatics Consortium (JBIC), Koto-ku, Tokyo, Japan; ${ }^{2}$ Department of Biotechnology, NITE Biotechnology Development Center (NBDC), National Institute of Technology and Evaluation (NITE), Kisarazu, Chiba, Japan; ${ }^{3}$ NITE Biological Resource Center (NBRC), National Institute of Technology and Evaluation (NITE), Kisarazu, Chiba, Japan and ${ }^{4}$ Biomedicinal Information Research Center (BIRC), National Institute of Advanced Industrial Science and Technology (AIST), Koto-ku, Tokyo, Japan

Correspondence: Dr M Takagi, Biomedicinal Information Research Center (BIRC), Japan Biological Informatics Consortium (JBIC), 2-42 Aomi, Koto-ku, Tokyo 135-0064, Japan. E-mail: motoki-takagi@aist.go.jp or Dr K Shin-ya, Biomedicinal Information Research Center (BIRC), National Institute of Advanced Industrial Science and Technology (AIST), 242 Aomi, Koto-ku, Tokyo 135-0064, Japan.

E-mail: k-shinya@aist.go.jp
}

Received 11 January 2009; revised 20 February 2009; accepted 23 February 2009; published online 13 March 2009 
<smiles>[R]CC(=O)C1CC2([R])C(=CC1=O)CCC(O)C2(C)Br</smiles>

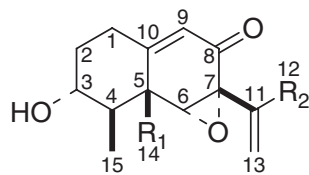

$\mathrm{R}_{1}=\mathrm{CH}_{2} \mathrm{OH} \quad \mathrm{R}_{2}=\mathrm{CH}_{3}$

$\mathrm{R}_{1}=\mathrm{R}_{2}=\mathrm{CH}_{3}$

$\mathrm{R}_{1}=\mathrm{CH}_{3}$
JBIR-28 (2)

sporogen-AO1

phomenone

Figure 1 Structures of JBIR-27 (1), -28 (2), petasol, sporogen-AO1 and phomenone.

rated to dryness. The dried residue $(1.012 \mathrm{~g})$ was chromatographed on normal-phase medium-pressure liquid chromatography developed with a $\mathrm{CHCl}_{3}-\mathrm{MeOH}$ gradient system, and fractions, including major metabolites, were collected by liquid chromatography-MS monitoring. As a result, sporogen-AO1 was obtained from $2 \%$ $\mathrm{MeOH}$ eluates. The $5 \% \mathrm{MeOH}$ eluate $(61.6 \mathrm{mg})$ was purified by preparative reversed-phase HPLC on an L-column2 ODS column developed with $35 \% \mathrm{MeOH}-\mathrm{H}_{2} \mathrm{O}$ containing $0.1 \%$ formic acid (flow rate: $\left.10 \mathrm{ml} \mathrm{min}^{-1}\right)$ to yield $\mathbf{1}(12.1 \mathrm{mg}$, Rt $14 \mathrm{~min}), 2$ (1.4 mg, Rt $11 \mathrm{~min}$ ) and phomenone (1.7 mg, Rt $9 \mathrm{~min})$. Compound 1 ( $4.8 \mathrm{mg}$, Rt $14 \mathrm{~min}$ ) was further purified by preparative reversed-phase HPLC on an X-bridge column developed with $35 \% \mathrm{MeOH}-\mathrm{H}_{2} \mathrm{O}$ containing $0.1 \%$ diethylamine (flow rate: $10 \mathrm{ml} \mathrm{min}^{-1}$ ).

\section{Structure elucidation}

The physicochemical properties of $\mathbf{1}$ and $\mathbf{2}$ are summarized in Table 1. Compound 1 was obtained as a colorless amorphous powder. The HR-MS spectrum of 1 established its molecular formula as $\mathrm{C}_{15} \mathrm{H}_{22} \mathrm{O}_{3}$ by HR-ESI-MS data $\left[\mathrm{m} / \mathrm{z} 251.1616(\mathrm{M}+\mathrm{H})^{+}\right]$. The IR spectrum showed absorbance for a hydroxyl $\left(v_{\max }, 3320 \mathrm{~cm}^{-1}\right)$ and an $\alpha, \beta$ unsaturated ketone $\left(v_{\max }, 1660 \mathrm{~cm}^{-1}\right)$ group, respectively. Their structures were determined by detailed analyses of a series of NMR spectra. The tabulated ${ }^{1} \mathrm{H}$ - and ${ }^{13} \mathrm{C}$-NMR spectral data obtained from heteronuclear single-quantum coherence spectrum are summarized in Table 2. Three partial structures were established by double-quantumfiltered-COSY and constant-time heteronuclear multiple-bond correlation spectra as follows (Figure 2).

The sequence from methylene protons $\mathrm{H}-1\left(\delta_{\mathrm{H}} 2.60\right.$ and 2.39) to a doublet methyl proton $\mathrm{H}-15\left(\delta_{\mathrm{H}} 1.10\right)$ through methylene protons $\mathrm{H}-2\left(\delta_{\mathrm{H}} 2.14\right.$ and 1.41), an oxymethine proton $\mathrm{H}-3\left(\delta_{\mathrm{H}} 3.69\right)$ and a methine proton $\mathrm{H}-4\left(\delta_{\mathrm{H}} 1.34\right)$ was observed in double-quantumfiltered-COSY spectrum. In addition, $\mathrm{H}-15$ showed ${ }^{1} \mathrm{H}-{ }^{13} \mathrm{C}$ longrange couplings to an oxymethine carbon $\mathrm{C}-3\left(\delta_{\mathrm{C}} 70.5\right)$, a methine carbon C- $4\left(\delta_{\mathrm{C}} 50.7\right)$ and a quaternary carbon C-5 $\left(\delta_{\mathrm{C}} 45.3\right)$ in the constant-time heteronuclear multiple-bond correlation spectrum. The constant-time heteronuclear multiple-bond correlations from doublet hydroxymethyl protons $\mathrm{H}-14\left(\delta_{\mathrm{H}} 3.90\right.$ and 3.85$)$ to a quaternary $s p^{2}$ carbon C-10 $\left(\delta_{\mathrm{C}} 167.5\right)$, a methylene carbon C-6 $\left(\delta_{\mathrm{C}} 40.4\right)$ and C-5, from $\mathrm{H}-1$ to an olefinic carbon $\mathrm{C}-9\left(\delta_{\mathrm{C}} 126.1\right)$ and $\mathrm{C}-10$ deduced that these carbons constructed a six-membered ring system. A spin coupling system was observed between methylene protons $\mathrm{H}-6\left(\delta_{\mathrm{H}}\right.$ 2.31 and 1.91) and a methine proton $\mathrm{H}-7\left(\delta_{\mathrm{H}} 3.63\right)$. The long-range couplings from $\mathrm{H}-6$ to $\mathrm{C}-5$, a methine carbon $\mathrm{C}-7\left(\delta_{\mathrm{C}} 51.6\right)$, a ketone carbon $\mathrm{C}-8\left(\delta_{\mathrm{C}} 201.2\right), \mathrm{C}-10$ and $\mathrm{C}-14$, from $\mathrm{H}-7$ to $\mathrm{C}-6$ and $\mathrm{C}-8$, from an olefinic proton $\mathrm{H}-9\left(\delta_{\mathrm{H}} 5.89\right)$ to C-1, C-5 and C-7 established an octalone ring structure involving of an $\alpha, \beta$-unsaturated carbonyl group. Finally, the long-range couplings from a singlet allylic methyl proton $\mathrm{H}-12\left(\delta_{\mathrm{H}} 1.67\right)$ to a quaternary $s p^{2}$ carbon $\mathrm{C}-11\left(\delta_{\mathrm{C}} 144.0\right)$, an exomethylene carbon $\mathrm{C}-13\left(\delta_{\mathrm{C}} 113.7\right)$ and $\mathrm{C}-7$, from exomethylene
Table 1 Physicochemical properties of 1 and 2

\begin{tabular}{lcc}
\hline & \multicolumn{1}{c}{$\mathbf{1}$} & $\mathbf{2}$ \\
\hline Appearance & Colorless amorphous & Colorless amorphous \\
& powder & powder \\
Melting point & $135^{\circ} \mathrm{C}$ & $120^{\circ} \mathrm{C}$ \\
{$[\alpha]_{D}^{25}(\mathrm{MeOH})$} & $+161.1(\mathrm{c} 0.5)$ & $+188.7(\mathrm{c} 0.2)$ \\
$\mathrm{HR}-\mathrm{ESI}-\mathrm{MS}(\mathrm{m} / \mathrm{z})$ found & $251.1616(\mathrm{M}+\mathrm{H})^{+}$ & $265.1424(\mathrm{M}+\mathrm{H})^{+}$ \\
Calcd & $251.1647\left(\right.$ for $\left.\mathrm{C}_{15} \mathrm{H}_{23} \mathrm{O}_{3}\right)$ & $265.1440\left(\right.$ for $\left.\mathrm{C}_{15} \mathrm{H}_{21} \mathrm{O}_{4}\right)$ \\
UV $\lambda_{\max }(\mathrm{MeOH})(\mathrm{nm})(\varepsilon)$ & $238(8700)$ & $237(11700)$ \\
IR $\left.v_{\max }(\mathrm{KBr})(\mathrm{cm})^{-1}\right)$ & 3320,1660 & 3330,1670 \\
\hline
\end{tabular}

Table $2{ }^{13} \mathrm{C}$ - and ${ }^{1} \mathrm{H}$-NMR data of 1 and 2 in $\mathrm{CD}_{3} \mathrm{OD}$

\begin{tabular}{|c|c|c|c|c|}
\hline \multirow[b]{2}{*}{ Position } & \multicolumn{2}{|r|}{1} & \multicolumn{2}{|r|}{2} \\
\hline & ${ }^{13} \mathrm{C}$ & ${ }^{1} H(J$ in $H z)$ & ${ }^{13} \mathrm{C}$ & ${ }^{1} H(J$ in $H z)$ \\
\hline 1 & 31.7 & $\begin{array}{l}2.60, \text { ddd }(14.7,9.6,5.0) \\
2.39, \text { ddd }(14.7,4.1,4.0)\end{array}$ & 30.7 & $\begin{array}{l}2.60, \text { ddd }(14.4,9.7,4.9) \\
2.37, \text { dt }(14.4,3.8)\end{array}$ \\
\hline 2 & 35.1 & $\begin{array}{l}2.14, \text { dddd }(14.5,5.0 \\
4.6,4.0) \\
1.41, \text { dddd }(14.5,10.9 \\
9.6,4.1)\end{array}$ & 35.1 & $\begin{array}{l}2.12, \text { dddd (14.3, 4.9, } \\
4.3,3.8) \\
1.38, \text { dddd (14.3 10.9, } \\
9.7,3.8)\end{array}$ \\
\hline 3 & 70.5 & 3.69 , dt $(10.9,4.6)$ & 70.2 & 3.59 , dt $(10.9,4.3)$ \\
\hline 4 & 50.7 & $1.34, \mathrm{dq}(10.9,7.0)$ & 44.3 & $1.78, \mathrm{dq}(10.9,7.0)$ \\
\hline 5 & 45.3 & & 47.8 & \\
\hline 6 & 40.4 & $\begin{array}{l}2.31, \text { dd }(13.5,5.2) \\
1.91, \text { dd }(14.3,13.5)\end{array}$ & 67.6 & $3.45, \mathrm{~s}$ \\
\hline 7 & 51.6 & 3.63, dd $(14.3,5.2)$ & 63.4 & \\
\hline 8 & 201.2 & & 194.5 & \\
\hline 9 & 126.1 & $5.89, \mathrm{~d}(1.6)$ & 123.8 & $5.78, d(1.7)$ \\
\hline 10 & 167.5 & & 160.8 & \\
\hline 11 & 144.0 & & 140.4 & \\
\hline 12 & 18.6 & $1.67, \mathrm{br} \mathrm{s}$ & 18.5 & 1.83, br s \\
\hline 13 & 113.7 & $4.87^{a}, 4.80, \mathrm{~m}$ & 112.5 & $5.20,5.03, \mathrm{~m}$ \\
\hline 14 & 64.7 & $\begin{array}{l}3.90, \mathrm{~d}(11.2) \\
3.85, \mathrm{~d}(11.2)\end{array}$ & 61.0 & $\begin{array}{l}3.93, \mathrm{~d}(11.3) \\
3.82, \mathrm{~d}(11.3)\end{array}$ \\
\hline 15 & 10.0 & $1.10, \mathrm{~d}(7.0)$ & 10.6 & $1.24, \mathrm{~d}(7.0)$ \\
\hline
\end{tabular}

aOverlapped.

protons $\mathrm{H}-13\left(\delta_{\mathrm{H}} 4.87\right.$ and 4.80$)$ to a methyl carbon C-12 $\left(\delta_{\mathrm{C}} 18.6\right)$ and $\mathrm{C}-7$, from $\mathrm{H}-7$ to $\mathrm{C}-11, \mathrm{C}-12$ and $\mathrm{C}-13$ revealed that an isopropenyl group was substituted at the position of C-7. The relative configuration of $\mathbf{1}$ was determined by NOESY spectrum. NOESY correlations were observed between $\mathrm{H}-3 / \mathrm{H}-15, \mathrm{H}-14 / \mathrm{H}-15, \mathrm{H}-7 / \mathrm{H}-14$ and $\mathrm{H}-4 /\left[\mathrm{H}-6 \mathrm{ax}\left(\delta_{\mathrm{H}} 1.91\right)\right]$. Thus, the structure, including relative stereochemistry of $\mathbf{1}$, was determined as shown in Figure 1. 


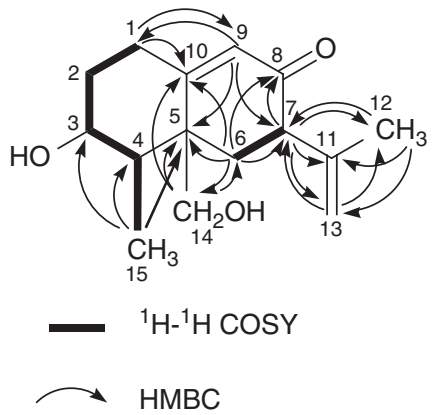

Figure 2 CT-HMBC and COSY correlations observed for $\mathbf{1}$.

Compound 2 was obtained as a colorless amorphous powder. The molecular formula of 2 was determined as $\mathrm{C}_{15} \mathrm{H}_{20} \mathrm{O}_{4}$, based on HR-ESI-MS data $\left[\mathrm{m} / \mathrm{z} 265.1424(\mathrm{M}+\mathrm{H})^{+}\right]$. The IR and UV spectra were similar to those of $\mathbf{1}$. Furthermore, the NMR spectral data were almost similar to those of $\mathbf{1}$ (Table 2), except for chemical shifts at C-6 and C-7. The typical ${ }^{13} \mathrm{C}$ chemical shifts, C-6 ( $\left.\delta_{\mathrm{C}} 67.6\right)$ and $\mathrm{C}-7$ $\left(\delta_{\mathrm{C}} 63.4\right)$, suggest an epoxy functional group. Thus, these data proved 2 to be 6,7-epoxyl JBIR-27 (Figure 1). The relative configuration of 2 was also determined by NOESY spectrum. NOESY correlations of 2 were observed between $\mathrm{H}-3 / \mathrm{H}-15, \mathrm{H}-14 / \mathrm{H}-15, \mathrm{H}-6 / \mathrm{H}-15$ and $\mathrm{H}-6 / \mathrm{H}-14$. Biosynthetically, the absolute configurations of $\mathbf{1}$ and $\mathbf{2}$ were assumed to be similar to those of petasol ${ }^{10}$ and sporogen-AO $1,{ }^{8}$ respectively, as these compounds were derivatives of petasol and/or sporogen-AO1 by oxygenation at C-14 in the skeleton (Figure 1).

We herein isolated two new eremophilane analogs, $\mathbf{1}$ and 2, from the culture broth of a tunicate-derived Penicillium sp. SS080624SCf1. Although eremophilane analogs are known to be isolated from many fungal metabolites, ${ }^{11-15}$ this paper is the first report that a tunicatederived Penicillium sp. produces terpenoid compounds.

\section{Biological activity}

To evaluate the cytotoxicity of 1,2 , sporogen-AO1 and phomenone against mammalian cells, we used human cervical carcinoma cell line HeLa. Sporogen-AO1, phomenone and 2 showed cytotoxicity against HeLa cells at IC $_{50}$ values of 8.3, 19 and $92 \mu \mathrm{M}$, respectively. In contrast, 1 had no cytotoxic activity at the concentration of $80 \mu \mathrm{m}$. Thus, these results suggest that the epoxy group and the methyl group at C-14 in sporogen-AO1 and phomenone might play important roles for the cytotoxic effects against HeLa cells. Sporogen-AO1 recently has been reported as an inhibitor of human inducible nitric-oxide synthase expression. ${ }^{16}$ Therefore, studies on detailed biological activities are now underway.

\section{METHODS}

\section{General experimental procedures}

Melting points were determined with a Yanagimoto micro melting point apparatus (Yanagimoto, Kyoto, Japan). Optical rotations were assigned on a SEPA-300 polarimeter (Horiba, Kyoto, Japan). HR-ESI (electrospray ionization)-MS data were recorded on an LCT-Premier XE mass spectrometer (Waters, Milford, MA, USA). UV and IR spectra were measured on a DU730 UV/Vis spectrophotometer (Beckman, Fullerton, CA, USA) and an FT-720 spectrophotometer (Horiba), respectively. NMR spectra were taken on an NMR System $500 \mathrm{NB}$ CL (Varian, Palo Alto, CA, USA) in $\mathrm{CD}_{3} \mathrm{OD}$ with the residual solvent peak as an internal standard $\left(\delta_{\mathrm{C}} 49.0, \delta_{\mathrm{H}} 3.30\right.$ p.p.m.). Normal-phase medium-pressure liquid chromatography was performed on a Purif-Pack SI-60 column (Moritex, Tokyo, Japan). Analytical reversed-phase HPLC was carried out using an L-column2 ODS column $(4.6$ i.d. $\times 150 \mathrm{~mm}$; Chemical Evaluation and Research Institute, Tokyo, Japan) with a 2996 photodiode array detector
(Waters) and a 3100 mass detector (Waters). Preparative reversed-phase HPLC was carried out using an L-column2 ODS (20 i.d. $\times 150 \mathrm{~mm})$ or an X-bridge column (20 i.d. $\times 150 \mathrm{~mm}$; Waters) with an L-2455 photodiode array detector (Hitachi High Technologies, Tokyo, Japan). Reagents and solvents were of the highest grade available.

\section{Microorganism}

The producing fungus, designated as SS080624SCf1, was isolated from a tunicate, D. molle, collected from Ishigaki Island, Okinawa Prefecture, Japan. The SS080624SCf1 strain was identified based on its ribosomal RNA ITS region and morphology observed under a Zeiss Axio Plan 2 imaging system (Carl Zeiss, Oberkochen, Germany).

\section{Medium}

The seed medium, potato dextrose was composed of $2.4 \mathrm{gl}^{-1}$ Potato Dextrose Broth (BD Biosciences, San Jose, CA, USA). The production medium consisted of $15 \mathrm{~g}$ brown rice (Hitomebore, Miyagi, Japan) and $45 \mathrm{ml}$ solution containing $0.67 \mathrm{gl}^{-1}$ Bacto-Yeast Extract (BD Biosciences), $0.33 \mathrm{gl}^{-1}$ sodium tartarate dihydrate (Kanto Chemical, Tokyo, Japan) and $0.33 \mathrm{gl}^{-1} \mathrm{~K}_{2} \mathrm{HPO}_{4}$ (Wako Pure Chemical, Tokyo, Japan) in a 500-ml Erlenmeyer flask.

\section{Cytotoxic assay}

Human cervical carcinoma cell line HeLa was used in this study. The cells were cultured in Dulbecco's modified Eagle's medium (Wako Pure Chemical) supplemented with $10 \%$ fetal bovine serum (Gibco, Carlsbad, CA, USA), penicillin $\left(100 \mathrm{U} \mathrm{ml}^{-1}\right)$ and streptomycin $\left(100 \mu \mathrm{g} \mathrm{ml}^{-1}\right)$ at $37^{\circ} \mathrm{C}$ in a humidified incubator with $5 \% \mathrm{CO}_{2}$. The cytotoxic activity was estimated by WST- 8 [2-(2-methoxy-4-nitrophenyl)-3-(4-nitrophenyl)-5-(2,4-disulfophenyl)-2H-tetrazolium, monosodium salt] colorimetric assay. HeLa cells were incubated on 96-well plates at a density of $5.0 \times 10^{3}$ cells per well in $100 \mu$ of medium for overnight, and then treated with compounds at various concentrations for $48 \mathrm{~h}$. Next, $10 \mu \mathrm{l}$ of WST- 8 reagent solution (Cell Counting Kit; Dojindo, Kumamoto, Japan) was added and incubated for an hour at $37^{\circ} \mathrm{C}$ in a humidified incubator with $5 \% \mathrm{CO}_{2}$. The absorbance of the formazan dye formed was measured at $450 \mathrm{~nm}$.

\section{ACKNOWLEDGEMENTS}

This study was supported by a grant from the New Energy and Industrial Technology Department Organization (NEDO) of Japan. We thank Mr Akihiko Kanamoto, OP BIO FACTORY Co. Ltd, for his help in collecting the tunicate sample.

1 Blunt, J. W. et al. Marine natural products. Nat. Prod. Rep. 25, 35-94 (2008).

2 Saleem, M. et al. Marine natural products of fungal origin. Nat. Prod. Rep. 24, 1142-1152 (2007).

3 Zhang, M. et al. Cytotoxic alkaloids and antibiotic nordammarane triterpenoids from the marine-derived fungus Aspergillus sydowi. J. Nat. Prod. 71, 985-989 (2008).

4 Sun, Y. et al. Trichodermatides A-D, novel polyketides from the marine-derived fungus Trichoderma reesei. Org. Lett. 10, 393-396 (2008).

5 Zhang, Y. et al. Carbonarones $A$ and $B$, new bioactive $\gamma$-pyrone and $\alpha$-pyridone derivatives from the marine-derived fungus Aspergillus carbonarius. J. Antibiot. 60, 153-157 (2007).

6 Belofsky, G. N., Anguera, M., Jensen, P. R., Fenical, W. \& Köck, M. Oxepinamides A-C and fumiquinazolines $\mathrm{H}-\mathrm{I}$ : bioactive metabolites from a marine isolate of a fungus of the genus Acremonium. Chemistry 6, 1355-1360 (2000).

7 Xin, Z. H. et al. Isocoumarin derivatives from the sea squirt-derived fungus Penicillium stoloniferum QY2-10 and the halotolerant fungus Penicillium notatum B-52. Arch. Pharm. Res. 30, 816-819 (2007).

8 Tirilly, Y., Kloosterman, J., Sipma, G. \& Kettenes-Van den Bosch, J. J. A fungitoxic sesquiterpene from Hansfordia pulvinata. Phytochemistry 22, 2082-2083 (1983).

9 Riche, C., Pascard-Billy, P., Devys, M., Gaudemer, A. \& Barbier, M. Structure crystalline et moleculaire de la phomenone, phytotoxine produite par le champignon. Tetrahedron Lett. 15, 2765-2766 (1974).

10 Sugama, K., Hayashi, K., Nakagawa, T., Mitsuhashi, H. \& Yoshida, N. Sesquiterpenoids from Petasites fragrans. Phytochemistry 22, 1619-1622 (1983).

11 Moreau, S., Gaudemer, A., Lablache-Combier, A. \& Biguet, J. Metabolites de Penicillium roqueforti: PR toxine et metabolites associes. Tetrahedron Lett. 11, 833-834 (1976). 
12 Sugawara, F. et al. Phytoactive eremophilanes produced by the weed pathogen Drechslera gigantean. Biosci. Biotech. Biochem. 57, 236-239 (1993).

13 Smith, C. J. et al. Novel sesquiterpenoids from the fermentation of Xylaria persicaria are selective ligands for the NPY Y5 receptor. J. Org. Chem. 67, 5001-5004 (2002).

14 MacDonald, L. A. et al. 07H239-A, a new cytotoxic eremophilane sesquiterpene from the marine-derived xylariaceous fungus LL-07H239. J. Nat. Prod. 67, 1565-1567 (2004).
15 Huang, Y. F., Qiao, L., Lv, A. L., Pei, Y. H. \& Tian, L. Eremophilane sesquiterpenes from the marine fungus Penicillium sp. BL27-2. Chin. Chem. Lett. 19, 562-564 (2008).

16 Yao, Y. et al. Sporogen, S14-95, and S-curvularin, three inhibitors of human inducible nitric-oxide synthase expression isolated from fungi. Mol. Pharmacol. 63, 383-391 (2003). 